\title{
EDITORIAL
}

\section{Born too Early, Where are We Now?}

\author{
Hermanto T Joewono
}

The World Health Organization ${ }^{1,2}$, AAP and ACOG $^{3}$ define preterm births as babies born alive before 37 completed weeks of pregnancy and WHO sub-categories based on gestational age: extremely preterm $(<28$ weeks), very preterm (28 to 32 weeks) and moderate to late preterm (32 to 37 weeks). Other classification: spontaneous PTBs - due to preterm labour (40 - 50\%) or preterm premature rupture of membranes (20 $30 \%$ ); and iatrogenic/ indicated: due to maternal or fetal issues that influence the health of the mother or fetus. Every year, 13 -15 million babies are born preterm, over 85\% occur in Asia and Africa, and this number is rising. Across 184 countries, the rate of PTB ranges from $5 \%$ to $18 \%$ of babies born., ${ }^{1,2}$ Preterm babies are the leading cause of death among children under five years of age, approximately one-third of all infant deaths in the United States or 1 million deaths every year, meaning every minute 2 babies die of PTBs. Since these deaths occur in infants supposed to live for 70 - 80 years, PTB represents one of the most important, if not the most important, the cause of years - of - life lost. ${ }^{4}$ For the most part, these are healthy babies. Preterm babies also account for approximately $45 \%$ of children with cerebral palsy, $35 \%$ of children with vision impairment, and $25 \%$ of children with cognitive or hearing impairment. ${ }^{4,5}$ There are many pathways from risk factors to the terminal cascade of events resulting in labour. Preterm labour likely occurs when local uterine factors prematurely stimulate this cascade, or suppressive factors that inhibit the cascade and maintain uterine quiescence are withdrawn prematurely. The four major factors leading to preterm labour are intrauterine infection, decidual haemorrhage, excessive uterine stretch, and maternal or fetal stress. Uteroplacental vascular insufficiency, exaggerated inflammatory response, hormonal factors, cervical insufficiency, and genetic predisposition also play a role. ${ }^{6}$ Biological domain show different perspectives and may complement the theories on PTBs. ${ }^{7-9}$

In accordance to WHO ten main recommendations (and 17 additional sub-recommendations) ${ }^{2}$ and Berghella optimism, interventions that can be suggested are, non medical: a statement of political will from the decision makers, developing community awareness, movement and national network for prevention PTBs (NNPPB) may be reasonable options (in accordance with Preterm Birth International Collaborative/PREBIC), before pregnancy: strengthening the family planning program to prevent adolescent pregnancy and avoiding too short or too long interpregnancy interval. Smoking and alcohol inhibitions, modify obesity and identify history preterm birth. ${ }^{10-12}$ During the first trimester screening by ultrasound, lab markers and improve the scoring system to predict PTBs. During the third trimester: accurate identification of women in true preterm labour allows appropriate of further intervention: tocolysis is to allow antenatal corticosteroids. Neuroprotection by magnesium sulfate administration before 32 weeks of gestation. ${ }^{13}$, after birth period: assessment of newborn by umbilical blood gas analysis, resuscitation by NRP method/algorithm, NICU preparation and admission if necessary, surfactant if appropriate and the more affordable method: Kangaroo care $^{2}$ and collaborative research between biologist and medicine to reveal pathophysiology of preterm labour and birth which in turn also reveal the physiologic mechanism of labour.

\section{References}

1. March of Dimes, PMNCH, Save the Children, WHO. Born Too Soon: The Global Action Report on Preterm Birth. Eds CP Howson, MV Kinney, JE Lawn. World Health Organization. Geneva, 2012.

2. World Health Organization. WHO recommendations on interventions to improve preterm birth outcomes. World Health Organization Geneva, 2015.

3. $\quad$ ACOG. Preterm birth. FAQ. 2016: 1-3.

4. Berghella V. Preface. In Berghella V (ed). Preterm Birth. Prevention and Management. Chisester: Wiley Blackwell. 2010: xiii

5. Mandy GT. Short-term complications of the preterm infant. Up to Date. July 2018. http://www.uptodate.com Accessed on August 2, 2018

6. Lockwood CJ. Pathogenesis of spontaneous preterm birth. Up to Date. July 2018. http://www.uptodate.com Accessed on August 2, 2018 
7. Grant B. Premature birth and labour: Why So Soon? Scien Mag, 2013: 1-9.

8. Phillips JB, Abbot P and Rokas A. Is preterm birth a human-specific syndrome? Evol Med Public Health. 2015: 136-48 doi:10.1093/emph/eov010.

9. Plunkett J, Doniger S, Orabona G, Morgan T, Haataja R, et al. An Evolutionary Genomic Approach to Identify Genes Involved in Human Birth Timing. PLoS Genetics: 2011. 10.1371/journal.pgen.1001365.

10. Davey MA, Watson L, Rayner JA, Rowlands S. Risk? scoring systems for predicting preterm birth with the aim of reducing associated adverse outcomes. Cochrane Database of Systematic Reviews 2015, Issue 10. Art. No.: CD004902. DOI: 10.1002/14651858.CD004902.pub5.

11. Lockwood CJ. Preterm labour. Clinical findings, diagnostics, evaluation, and initial treatment. UpToDate. July 2018.http://www.uptodate.com Accessed on August 2, 2018.

12. Robinson JN, Norwitz ER. Preterm birth: Risk factors and interventions for risk reduction. UpToDate. October 2017http://www.uptodate.com Accessed on August 2, 2018.

13. Chollat C, Sentilhes L and Marret S. 2018. Fetal Neuroprotection by Magnesium Sulfate: From Translational Research to Clinical Application. Front. Neurol. 9:247. doi: 10.3389/fneur.2018.00247 